\title{
Curative effect of posterior lumbar interbody fusion in the treatment of single-segment lumbar degenerative disease and changes in adjacent segment quantitative score
}

\author{
YAN ZHUANG, FENG ZHOU, YUNQIN ZHANG and ZHENG JIN \\ Department of Orthopedics, The Affiliated Jiangyin Hospital of Southeast University \\ Medical College, Wuxi, Jiangsu 214400, P.R. China \\ Received November 16, 2017; Accepted May 9, 2018
}

DOI: $10.3892 /$ etm.2018.6159

\begin{abstract}
Curative effect of posterior lumbar interbody fusion (PLIF) in the treatment of single-segment lumbar degenerative disease and changes in adjacent segment quantitative score was investigated. A total of 86 patients with single-segment lumbar degenerative disease were randomly selected and divided into control group $(n=43)$ and observation group $(n=43)$. The control group was treated with posterolateral lumbar fusion, while the observation group was treated with PLIF. The observation group had a significantly longer operation time and shorter hospitalization time compared with the control group $(\mathrm{P}<0.05)$. The excellent-good rate of treatment in the observation group $(90.69 \%)$ was obviously higher than that in the control group $(62.79 \%)(\mathrm{P}<0.05)$. The levels of creatine phosphokinase in the two groups were significantly increased at 1,3 and 5 days after operation $(\mathrm{P}<0.05)$, and reached the peak at 1 day after operation and returned to normal basically at 7 days after operation. Oswestry disability index in the observation group at 1, 6 and 12 months after operation were significantly lower than those in the control group $(\mathrm{P}<0.05)$. There was no significant difference in the MRI-T2 relaxation time of multifidus muscle at 3 months after operation between the two groups $(\mathrm{P}>0.05)$. The grade I and II interbody fusion rates in the observation group at 12 months after operation were significantly higher than those in the control group $(\mathrm{P}<0.05)$. The mean spinal canal areas and adjacent segment quantitative scores in the two groups after operation were significantly improved compared with those before operation, and they were improved more obviously in the observation group than those in the control group $(\mathrm{P}<0.05)$. PLIF has a
\end{abstract}

Correspondence to: Dr Zheng Jin, Department of Orthopedics, The Affiliated Jiangyin Hospital of Southeast University Medical College, 163 Shoushan Road, Jiangyin, Wuxi, Jiangsu 214400, P.R. China

E-mail: zhuangyan_bmu@126.com

Key words: posterior lumbar interbody fusion, single-segment lumbar degenerative disease, adjacent segment quantitative score more definite short-term curative effect and a higher interbody fusion rate in the treatment of single-segment lumbar degenerative disease, which is more conducive to promoting the postoperative rehabilitation of patients and slowing down the occurrence of adjacent segment degeneration.

\section{Introduction}

Lumbar degenerative disease is one of the common orthopedic diseases, mainly including protrusion of lumbar intervertebral disc, lumbar spinal stenosis, scoliosis and lumbar spondylolisthesis, which is complicated with or without low back pain and intermittent claudication $(1,2)$. Patients are usually treated due to unbearable low back pain (3). Lumbar degenerative disease is one of the major factors leading to disability in the working population. After the conservative treatment failes, patients can be treated via surgery, which will shorten the recovery time and alleviate the symptoms (4). Posterior lumbar interbody fusion (PLIF) is a surgical method that started to be used and promoted clinically in the 1950 s, which can effectively stabilize the patient's spine, maintain the intervertebral height, enhance the anterior spinal bearing and relieve the nerve compression (5). In this study, patients with single-segment lumbar degenerative disease were treated with different surgical methods, and the curative effects were compared, so as to provide a basis for the development and implementation of reasonable treatment plan.

\section{Patients and methods}

Basic information for the included patients. A total of 86 patients with single-segment lumbar degenerative disease treated in Jiangyin Hospital (Jiangyin, Wuxi, China), from January 2013 to October 2016 were randomly selected. Inclusion criteria: i) patients diagnosed with single-segment lumbar degenerative disease via imaging examination; ii) patients with intermittent claudication complicated with or without low back pain or lower limb radiation pain and who received conservative treatment that failed for 6 months; iii) patients receiving single-segment surgery; iv) patients who signed the informed consent. Exclusion criteria: i) patients with multi-segment lumbar spinal stenosis or protrusion of 
intervertebral disc; ii) patients with severe osteoporosis or intervertebral space infection. This study was approved by the Ethics Committee of the Affiliated Jiangyin Hospital of Southeast University Medical School (Jiangyin, Wuxi, China). Signed informed consents were obtained from all participants before the study. The patients were divided into control group $(n=43)$ and observation group $(n=43)$ using a random number table. The control group was treated with posterolateral lumbar fusion (PLF), while the observation group was treated with PLIF. There were no statistically significant differences in the general data of patients between the two groups $(\mathrm{P}>0.05)$ (Table I).

Preoperative preparation. Before operation, patients were comprehensively evaluated to exclude surgical contraindications, and the square titanium alloy cage was chosen. The appropriate operation time of patients was selected; both groups of patients received the operation under combined spinal-epidural anesthesia.

Surgical procedures. Under the prone position, a posterior median incision $(8-10 \mathrm{~cm})$ was made on the back of patients in both groups, and the deep fascia and paravertebral muscle was peeled off to expose the vertebral plate lesion and one upper and one lower normal vertebral plate, and they were fixed firmly using the fix screws. The control group was treated with PLF for total or semi-laminectomy; the vertebral spinous process was removed using rongeur forceps and the proliferative ligamentum flavum was cleared; the vertebral plates causing stenosis was expanded and removed for effective decompression. After the reduction fixation via pedicle screw system, the vertebral plate was washed with normal saline; the spinous process and vertebral plate was removed and trimmed into the bone block in appropriate size and implanted into the intervertebral space, followed by drainage tube indwelling and incision suture layer by layer.

The observation group was treated with PLIF, and the total laminectomy was performed for the affected vertebrae. The nerve root was fully decompressed and the upper and lower adjacent segment stenosis received the potential decompression to fully expose the spinous process and the bilateral vertebral plates. The articular process was retained as far as possible, the connecting rods were connected, and the intervertebral space was expanded moderately using the distracter; the posterior vertebral osteophyte and intervertebral disc tissues were completely removed, and the upper and lower cartilage endplates and residual disc tissues were remove; the cage was chosen according to the height of intervertebral space; the spinous process and vertebral plate removed were cut into pieces of bone and implanted into the front section of intervertebral space; the single cage was implanted into the second half of intervertebral space $(\sim 3 \mathrm{~mm}$ away from the posterior margin of vertebral body); then the horizontal connection was installed to ensure the spinal stability. After the spinal dura mater was covered with gelatin sponge, the drainage tube was placed and the incision was sutured.

Postoperative care. After operation, patients rested under supine position and were treated with conventional dehydration, infection prevention and neurotrophic drugs. At $36 \mathrm{~h}$ after operation, the drainage tube was removed and patients received training for straight-leg-raising and waist function at $72 \mathrm{~h}$ after operation. After 1 week, they exercised off the bed wearing waist belt for no less than 3 months; after the drainage tube was removed, the internal fixation was observed via the lumbar anteroposterior and lateral film and flexion-extension film. Magnetic resonance imaging (MRI) was performed at 3 months after operation. The MRI-T2 relaxation time was measured for the multifidus muscle in the central plane of fusion segment $(\sim 1.5 \times 1.5 \mathrm{~cm})$. The patients were followed up for 12 months after operation and the rehabilitation was evaluated.

Evaluation indexes. The clinical surgical effect of patients was compared, including operation time, bleeding amount (intraoperative bleeding amount + postoperative drainage amount) and hospitalization time. Patients were followed up for 1 year, and the function was evaluated according to MacNab score: i) excellent, the patient can raise the leg straight for $>70^{\circ}$, the muscle strength and exercise of lower limb are normal, and the low back pain has disappeared; ii) good, the patient can raise the leg straight for $30^{\circ}$ more than that before operation, but $<70^{\circ}$, the muscle strength is level 4 , and they can work and live normally accompanied occasionally with slight waist-leg pain; iii) general, the patients can raise the leg straight for $15^{\circ}$ more than that before operation, but $<30^{\circ}$, the muscle strength is level 3, and the low back pain is alleviated; but they still take drugs occasionally; iv) poor, there is no change before and after operation or even exacerbation, and analgesics are still needed; excellent-good rate $=($ excellent + good $) /$ total cases .

Oswestry disability index (ODI). The patient's dysfunction was scored according to the ODI (0-5 points: 0 , no dysfunction; 5 points, the most obvious dysfunction) from a total of 9 items in 3 dimensions: individual capacity, pain and personal comprehensive ability. ODI is positively correlated with the degree of dysfunction. The levels of creatine phosphokinase (CPK) in patients were measured at 1,3,5 and 7 days after operation to evaluate the muscle injury.

Bridwell fusion grading. At 12 months after operation, the fusion degree was evaluated via anterioposterior and lateral film and over flexion-extension X-ray according to Bridwell fusion grading criteria (6): i) grade I, bone graft reconstruction and fusion, and ingrowth of bone trabecula; ii) grade II, complete bone graft, incomplete reconstruction fusion, but no translucent area; iii) grade III, complete bone graft, and potential translucent area below and above the bone block; iv) grade IV, collapsed and absorbed bone block, and no bone fusion. The MRI was performed at 3 months for the multifidus muscle after operation to detect the MRI-T2 relaxation time.

Pfirrmann grading. The adjacent segment was scored (0-10 points) using Pfirrmann grading method (7) combined with the patient's clinical data. Scoring method: i) Pfirrmann grading: grade I, 4 points; grade II, 3 points; grade III, 2 points; grade IV, 1 point; grade V, 0 point; ii) imaging findings: adjacent segment sagittal plane angle $\geq 10^{\circ}, 1$ point; lateral dislocation $\leq 3 \mathrm{~mm}, 1$ point; cone shaped deformation of intercalated disc $\leq 5^{\circ}, 1$ point; sagittal dislocation $\leq 4 \mathrm{~mm}, 1$ point; 
Table I. General data of patients.

\begin{tabular}{|c|c|c|c|c|}
\hline Items & Control group $(n=43)$ & Observation group $(n=43)$ & $\mathrm{t} / \chi^{2}$ & P-value \\
\hline Sex (male/female) & $23 / 20$ & $21 / 22$ & 0.046 & 0.829 \\
\hline Age (years) & $45-75$ & $45-80$ & & \\
\hline Average age (years) & $58.74 \pm 8.57$ & $58.89 \pm 8.38$ & 0.082 & 0.934 \\
\hline Course of disease (month) & $23.83 \pm 3.54$ & $24.16 \pm 3.27$ & 0.449 & 0.654 \\
\hline \multicolumn{5}{|l|}{ Surgical segment $(\mathrm{n}, \%)$} \\
\hline L4/L5 & $29(67.44)$ & $27(62.79)$ & 0.051 & 0.821 \\
\hline L5/S1 & $14(32.56)$ & $16(37.21)$ & & \\
\hline \multicolumn{5}{|l|}{ Symptom (n, \%) } \\
\hline Lumbar spinal stenosis & $18(41.86)$ & $19(44.19)$ & 0.262 & 0.877 \\
\hline Protrusion of lumbar intervertebral disc & $14(32.55)$ & $15(34.88)$ & & \\
\hline Lumbar spondylolisthesis & $11(25.58)$ & $9(20.93)$ & & \\
\hline
\end{tabular}

Table II. Comparison of clinical operation effects between the two groups.

\begin{tabular}{|c|c|c|c|c|c|}
\hline Groups & $\mathrm{n}$ & $\begin{array}{l}\text { Operation time } \\
\qquad(\min )\end{array}$ & $\begin{array}{c}\text { Intraoperative bleeding } \\
\text { amount }(\mathrm{ml})\end{array}$ & $\begin{array}{l}\text { Postoperative drainage } \\
\text { amount }(\mathrm{ml})\end{array}$ & $\begin{array}{l}\text { Hospitalization } \\
\text { time (days) }\end{array}$ \\
\hline Observation group & 43 & $196.83 \pm 23.62$ & $371.47 \pm 26.63$ & $237.86 \pm 17.45$ & $7.23 \pm 1.53$ \\
\hline Control group & 43 & $148.14 \pm 23.57$ & $367.57 \pm 29.38$ & $231.97 \pm 18.37$ & $12.56 \pm 1.47$ \\
\hline $\mathrm{t}$ value & & 9.568 & 0.766 & 1.524 & 16.437 \\
\hline P-value & & $<0.001$ & 0.446 & 0.131 & $<0.001$ \\
\hline
\end{tabular}

iii) clinical data: patients aged $\leq 60$ years, 1 point; body mass index $(\mathrm{BMI}) \leq 25,1$ point. The average spinal canal area was calculated via MRI imaging.

Statistical analysis. SPSS 19.0 (IBM Corp., Armonk, NY, USA) software was used for data processing. Comparison between groups was done using One-way ANOVA test followed by Post Hoc Test (Least Significant Difference). Enumeration data were presented as ratio, and Chi-square test was used. Rank sum test was used for ranked data. $\mathrm{P}<0.05$ was considered to indicate a statistically significant difference.

\section{Results}

Comparison of clinical operation effects between the two groups. There were no significant differences in the intraoperative bleeding amount and postoperative drainage amount between the two groups $(\mathrm{P}>0.05)$; the operation time in the observation group was significantly longer than that in the control group, but the hospitalization time was significantly shorter than that in the control group $(\mathrm{P}<0.05)$ (Table II).

Evaluation of therapeutic effects on patients in the two groups via MacNab score. The excellent-good rate of treatment in the observation group $(90.69 \%)$ was significantly higher than that in the control group $(62.79 \%)(\mathrm{P}<0.05)$ (Table III).

Comparison of CPK levels in the two groups before and after operation. Before operation, the CPK level was 71.83 $\pm 3.14 \mathrm{U} / 1$
Table III. Comparison of therapeutic effects on patients between the two groups $(n, \%)$.

\begin{tabular}{lccccc}
\hline Groups & $n$ & Excellent & Good & General & Poor \\
\hline $\begin{array}{l}\text { Observation } \\
\text { group }\end{array}$ & 43 & $23(53.48)$ & $16(37.21)$ & $2(4.65)$ & $1(2.32)$ \\
$\begin{array}{l}\text { Control } \\
\text { group }\end{array}$ & 43 & $17(39.53)$ & $11(25.58)$ & $7(16.28)$ & $8(18.61)$ \\
\hline
\end{tabular}

in the observation group and 71.06 $\pm 3.23 \mathrm{U} / 1$ in the control group, respectively, and the difference was statistically significant $(\mathrm{P}>0.05)$; at 1,3 and 5 days after operation, the CPK levels were $523.16 \pm 9.13,242.35 \pm 7.14$ and $161.03 \pm 6.12 \mathrm{U} / 1$ in the observation group and $534.36 \pm 9.25,247.08 \pm 7.26$ and $162.76 \pm 6.17 \mathrm{U} / 1$ in the control group, which were increased compared with those before operation $(\mathrm{P}<0.05)$. The CPK level reached the peak at 1 day after operation, and it was $78.61 \pm 3.14 \mathrm{U} / 1$ in the observation group and $79.15 \pm 3.48 \mathrm{U} / 1$ in the control group at 7 days after operation, respectively. There were no significant differences in the CPK levels at different time-points after operation between the two groups ( $\mathrm{P}>0.05)$ (Fig. 1).

Comparison of ODIs between the two groups. ODIs in observation group at 1, 6 and 12 months after operation were significantly lower than those in the control group, and the differences were statistically significant $(\mathrm{P}<0.05)$ (Table IV). 


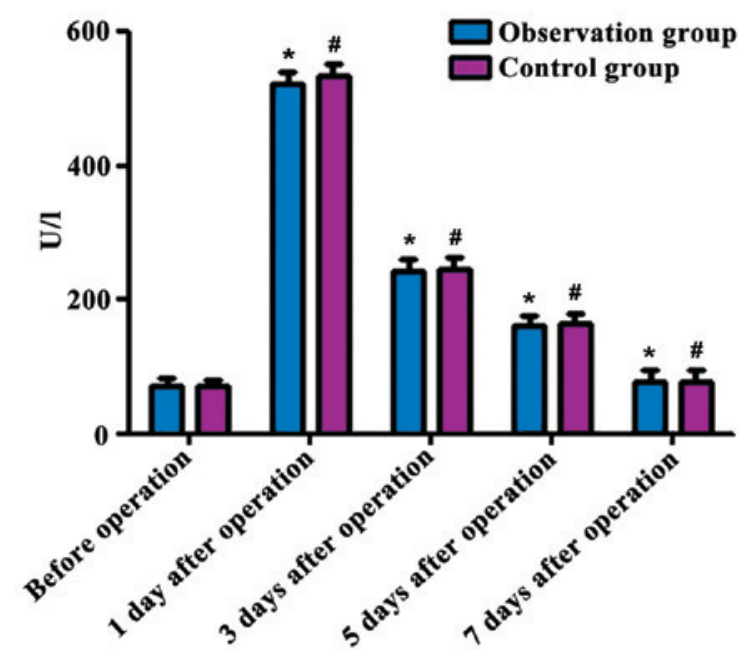

Figure 1. CPK levels in the two groups before and after operation. CPK, creatine phosphokinase." $\mathrm{P}<0.05$, compared with the observation group before surgery; ${ }^{\#} \mathrm{P}<0.05$, compared with the control group before surgery.

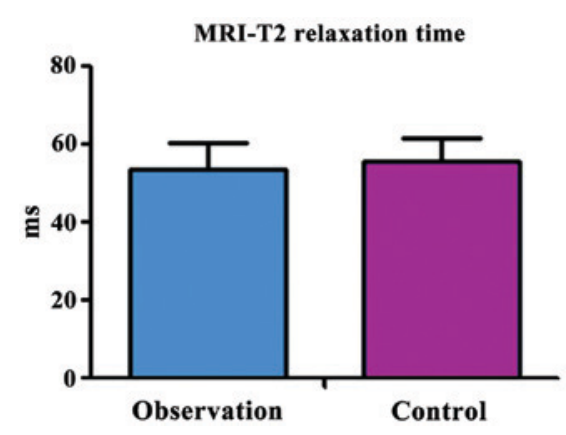

Figure 2. MRI-T2 relaxation time at 3 months after surgery between the two groups. MRI, magnetic resonance imaging.

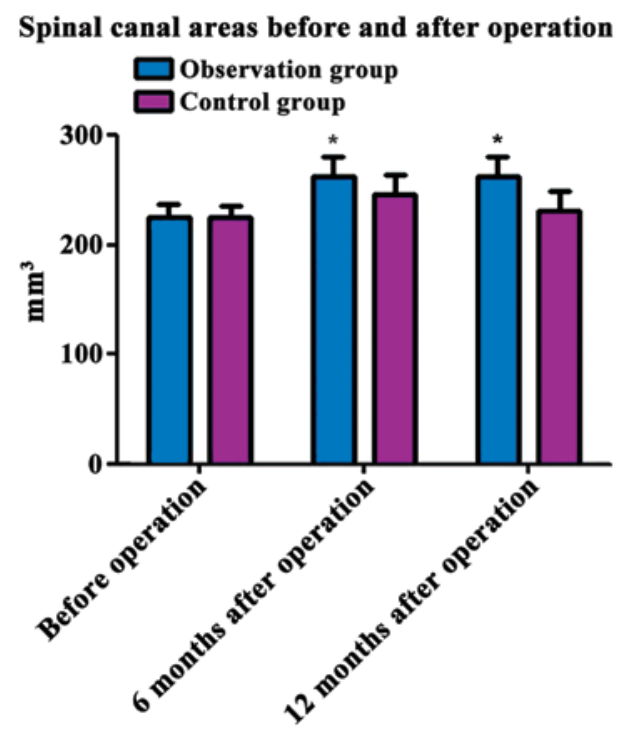

Figure 3. Spinal canal areas before and after operation between the two groups. " $\mathrm{P}<0.05$, compared with the control group.

Comparison of fusion rates between the two groups. Patients were followed up for 1 year; the grade I and II interbody fusion rates in the observation group $(93.02 \%)$ were significantly
Table IV. Comparison of ODIs between the two groups.

\begin{tabular}{lccccc}
\hline Groups & $\mathrm{n}$ & $\begin{array}{c}\text { Before } \\
\text { operation }\end{array}$ & $\begin{array}{c}1 \text { month } \\
\text { after } \\
\text { operation }\end{array}$ & $\begin{array}{c}6 \text { months } \\
\text { after } \\
\text { operation }\end{array}$ & $\begin{array}{c}12 \text { months } \\
\text { after } \\
\text { operation }\end{array}$ \\
\hline $\begin{array}{l}\text { Observation } \\
\text { group }\end{array}$ & 43 & $30.81 \pm 3.24$ & $11.62 \pm 3.63$ & $5.78 \pm 2.24$ & $4.13 \pm 2.23$ \\
$\begin{array}{l}\text { Control } \\
\text { group }\end{array}$ & 43 & $30.29 \pm 2.34$ & $15.53 \pm 3.37$ & $7.93 \pm 2.36$ & $6.76 \pm 2.35$ \\
t value & & 0.853 & 5.176 & 4.333 & 5.323 \\
\begin{tabular}{l} 
P-value \\
\hline
\end{tabular} & 0.396 & $<0.001$ & $<0.001$ & $<0.001$ \\
\hline
\end{tabular}

ODI, oswestry disability index.

Table V. Comparison of postoperative fusion rates between the two groups.

\begin{tabular}{lccccc}
\hline $\begin{array}{l}\text { Groups } \\
\text { Observation }\end{array}$ & 43 & $26(60.47)$ & $14(32.56)$ & $3(6.98)$ & $0(0.00)$ \\
$\begin{array}{l}\text { group } \\
\begin{array}{l}\text { Control } \\
\text { group }\end{array}\end{array}$ & 43 & $20(46.51)$ & $12(27.91)$ & $10(23.26)$ & $1(2.33)$ \\
$\chi^{2}$ & & & & & \\
P-value & & & 4.181 & \\
\hline
\end{tabular}

Table VI. Comparison of adjacent segment quantitative scores before and after operation between the two groups.

\begin{tabular}{lcccc}
\hline Groups & $\mathrm{n}$ & $\begin{array}{c}\text { Before } \\
\text { operation }\end{array}$ & $\begin{array}{c}6 \text { months } \\
\text { after operation }\end{array}$ & $\begin{array}{c}12 \text { months } \\
\text { after operation }\end{array}$ \\
\hline $\begin{array}{l}\text { Observation } \\
\text { group }\end{array}$ & 43 & $2.82 \pm 0.34$ & $4.56 \pm 0.35$ & $6.24 \pm 0.36$ \\
$\begin{array}{l}\text { Control } \\
\text { group }\end{array}$ & 43 & $2.78 \pm 0.32$ & $3.34 \pm 0.33$ & $4.89 \pm 0.34$ \\
t value & & 0.562 & 16.631 & 17.878 \\
P-value & 0.576 & $<0.001$ & $<0.001$ \\
\hline
\end{tabular}

higher than those in the control group (74.41\%); the differences were statistically significant $(\mathrm{P}<0.05)$ (Table V).

Comparison of MRI-T2 relaxation time at 3 months after operation between the two groups. The MRI-T2 relaxation time was $53.83 \pm 5.24 \mathrm{msec}$ in the observation group and $55.64 \pm 6.47 \mathrm{msec}$ in the control group, and there was no significant difference between the two groups $(t=1.426$, $\mathrm{P}=0.157$ ) (Fig. 2).

Comparison of spinal canal areas before and after operation between the two groups. Before operation, the spinal canal area was $224.83 \pm 13.14 \mathrm{~mm}^{3}$ in the observation group and $225.06 \pm 13.23 \mathrm{~mm}^{3}$ in the control group, and the difference was not statistically significant $(\mathrm{P}>0.05)$. At 6 and 12 months after operation, the spinal canal areas in the observation group $\left(263.16 \pm 9.13\right.$ and $\left.262.35 \pm 7.14 \mathrm{~mm}^{3}\right)$ were significantly 
larger than those in the control group $(246.36 \pm 9.25$ and $\left.231.08 \pm 7.26 \mathrm{~mm}^{3}\right)$; the differences were statistically significant $(\mathrm{P}<0.05)$ (Fig. 3).

Comparison of adjacent segment quantitative scores before and after operation between the two groups. At 6 months and 12 months after operation, the scores were $4.54 \pm 0.34$ and $6.12 \pm 0.53$ points in the observation group, and $3.58 \pm 0.46$ and $4.87 \pm 0.57$ points in the control group; the scores in the observation group were significantly superior to those in the control group, and the differences were statistically significant $(\mathrm{P}<0.05)$ (Table VI).

\section{Discussion}

Degeneration is the normal aging process of human body. Walking upright exerts large pressure to the lumbar vertebra, and it begins to degenerate after the age of 20 years. According to statistics, $\sim 90 \%$ of people aged $>50$ years suffer from varying degrees of spinal structure or lumbar intervertebral disc degeneration (8). Lumbar degeneration usually begins from the intervertebral disc, and with the increase of age and long-term repeated abrasion, intervertebral disc nucleus suffers from continuous dehydration and calcification, leading to uneven pressure dispersion and resulting in uneven stress to the peripheral fibrous rings; and it leads to intervertebral height loss and spinal instability, thereby increasing the oppression against the intervertebral disc and forming a vicious cycle (9). The combined action among protrusion of intervertebral disc, ligamentum flavum relaxation thickening, superior articular process hyperplasia and vertebral posterior margin hyperostosis leads to degenerative lumbar spinal stenosis. The initial symptom of lumbar degeneration is low back pain, and neurological dysfunction and intermittent claudication will occur with the progression of disease, causing inconvenience to the daily life of patients $(10,11)$.

The treatment of lumbar degenerative diseases can be divided into conservative treatment and surgical treatment. The conservative treatment usually includes general treatment (waist protection, back muscle exercise, pelvic traction and bed rest), physical therapy (massage, cupping, acupuncture and magnetic therapy), and drug therapy (steroids, analgesics and antispasmodic drugs) (12). The conservative treatment is the preferred method for most patients, which can effectively delay and prevent the disease. However, there are often some problems in conservative treatment: patients have poor tolerance to the pain in conservative treatment, the nervous system injury progresses rapidly, and cauda equina symptoms occur; conservative treatment is invalid for some patients, so the spinal decompression and spinal fusion should be considered via surgery at this time, thus effectively solving the spinal instability and pain relief (13). Spinal fusion may include transforaminal lumbar interbody fusion (TLIF), anterior lumbar interbody fusion (ALIF), PLF and PLIF (14). PLIF can not only relieve pain effectively through the nerve decompression, but also effectively maintain the intervertebral height and stability of surgical segment through cage placing, so that the biomechanical properties are superior, the bone graft fusion area is larger and the fusion effect is better (15).
Many studies have shown that the bone graft fusion internal fixation effect of PLIF is more significant than that of PLF, the fusion rate is higher, and the postoperative long-term effective rate is $\sim 95 \%$. The results of this study showed that ODIs at 1,6 and 12 months after operation in the observation group were significantly lower than those in the control group $(\mathrm{P}<0.05)$. The grade I and II fusion rates in the observation group at 12 months after operation was $90.69 \%$, which was significantly higher than that in the control group $(\mathrm{P}<0.05)$. In PLIF, intervertebral disc is removed, and nucleus pulposus and fibrous ring tissues are completely eliminated, and the intervertebral height can be increased and the lumbar sagittal axis can be reconstructed through a cage, thus improving the intervertebral foramen stenosis more effectively. PLF is usually limited in the intervertebral foramen and lateral recess decompression, and the incomplete decompression will still leave the nerve root compression symptoms after operation, so the postoperative decline in ODI is not as significant as PLIF (16). Using the cage can effectively avoid implanted bone displacement and compression, so as to provide good fusion conditions and share the burden of spin and increase the fusion area, and its fusion time is shorter and the effect is better than PLF (17). The CPK levels in the two groups were significantly increased at 1,3 and 5 days after operation $(\mathrm{P}<0.05)$, reached the peak at 1 day after operation and returned to normal at 7 days after operation. There was no statistically significant difference between the two groups $(\mathrm{P}>0.05)$. The incisions in the two surgeries is longer, and the scope of invasion is relatively wide, so the rapid increase in CPK level at 1 day after operation indicates a greater degree of muscle damage; the wound is healed with time under careful postoperative care for patients, so the CPK level is gradually decreased. There was no significant difference in MRI-T2 relaxation time of multifidus muscle between the two groups at 3 months after operation, indicating that there is no significant difference in muscle injury between the two surgeries and the muscle function is gradually restored with time (18).

In this study, patients were followed up for 12 months; the spinal canal area in the observation group was significantly larger than that in the control group, and the maintenance time of improved spinal canal area was also longer in the observation group, possibly because PLIF can effectively eliminate the fibrous ring protrusion and ligamentum flavum folding, so that the improving effect on spinal canal area is more obvious and more durable (19). The results of this study showed that the adjacent segment quantitative scores in observation group at 6 and 12 months after operation were significantly superior to those in the control group. This is because in PLIF, the cage is implanted into the intervertebral space and the lumbar kyphosis can be converted into lordosis via compression and fixation; the physiological flexion of lumbar spine can be restored, making its activity similar to normal spine, effectively reducing the adjacent vertebral slippage, compensatory activity and stress, so as to avoid the occurrence of degeneration. The effect of PLIF on the adjacent segment is less than that of PLF (5).

In conclusion, there are no significant differences in the effects of PLIF and PLF on soft tissue and muscle damage in the treatment of single-segment lumbar degenerative disease, but the cure rate of PLIF is significantly higher than that of 
PLF, the former of which can promote the early functional recovery of patients, increase the lumbar fusion rate, reduce the impact on adjacent segments and delay the degradation of adjacent segments.

\section{Acknowledgements}

Not applicable.

\section{Funding}

No funding was received.

\section{Availability of data and materials}

All data generated or analyzed during this study are included in this published article.

\section{Authors' contributions}

YaZ and ZJ designed the study and performed the experiments. YaZ, FZ and YuZ collected the data. YaZ and FZ analyzed the data, YaZ and ZJ prepared the manuscript. All authors read and approved the final manuscript.

\section{Ethics approval and consent to participate}

This study was approved by the Ethics Committee of the Affiliated Jiangyin Hospital of Southeast University Medical School (Jiangyin, Wuxi, China). Signed informed consents were obtained from all participants before the study.

\section{Consent for publication}

Patients or their guardians have provided written informed consents for publication.

\section{Competing interests}

The authors declare that they have no competing interests.

\section{References}

1. Kreiner DS, Shaffer WO, Baisden JL, Gilbert TJ, Summers JT, Toton JF, Hwang SW, Mendel RC and Reitman CA; North American Spine Society: An evidence-based clinical guideline for the diagnosis and treatment of degenerative lumbar spinal stenosis (update). Spine J 13: 734-743, 2013.

2. Manchikanti L, Benyamin RM, Falco FJ, Kaye AD and Hirsch JA: Do epidural injections provide short- and long-term relief for lumbar disc herniation? A systematic review. Clin Orthop Relat Res 473: 1940-1956, 2015.

3. Shamji MF, Mroz T, Hsu W and Chutkan N: Management of degenerative lumbar spinal stenosis in the elderly. Neurosurgery 77 (Suppl 4): S68-S74, 2015.

4. Shin JS, Oh SH and Cho PG: Surgical outcome of a zero-profile device comparing with stand-alone cage and anterior cervical plate with iliac bone graft in the anterior cervical discectomy and fusion. Korean J Spine 11: 169-177, 2014.
5. Hikata T, Kamata M and Furukawa M: Risk factors for adjacent segment disease after posterior lumbar interbody fusion and efficacy of simultaneous decompression surgery for symptomatic adjacent segment disease. J Spinal Disord Tech 27: 70-75, 2014.

6. Daubs MD, Lenke LG, Bridwell KH, Kim YJ, Hung M, Cheh G and Koester LA: Does correction of preoperative coronal imbalance make a difference in outcomes of adult patients with deformity? Spine 38: 476-483, 2013.

7. Urrutia J, Besa P, Campos M, Cikutovic P, Cabezon M, Molina M and Cruz JP: The Pfirrmann classification of lumbar intervertebral disc degeneration: An independent inter- and intra-observer agreement assessment. Eur Spine J 25: 2728-2733, 2016.

8. Williams FM and Sambrook PN: Neck and back pain and intervertebral disc degeneration: Role of occupational factors. Best Pract Res Clin Rheumatol 25: 69-79, 2011.

9. Li Z, Li F, Yu S, Ma H, Chen Z, Zhang H and Fu Q: Two-year follow-up results of the Isobar TTL Semi-Rigid Rod System for the treatment of lumbar degenerative disease. J Clin Neurosci 20: 394-399, 2013.

10. Cui YZ, Yang XH, Liu PF, Wang B and Chen WJ: Preliminary study on diagnosis of lumbar disc degeneration with magnetic resonance T1p, T2 mapping and DWI quantitative detection technologies. Eur Rev Med Pharmacol Sci 20: 3344-3350, 2016.

11. Choudhri TF, Mummaneni PV, Dhall SS, Eck JC, Groff MW, Ghogawala Z, Watters WC III, Dailey AT, Resnick DK, Sharan A, et al: Guideline update for the performance of fusion procedures for degenerative disease of the lumbar spine. Part 4: Radiographic assessment of fusion status. J Neurosurg Spine 21: 23-30, 2014.

12. Yu SW, Yang SC, Ma CH, Wu CH, Yen CY and Tu YK: Comparison of Dynesys posterior stabilization and posterior lumbar interbody fusion for spinal stenosis L4L5. Acta Orthop Belg 78: 230-239, 2012.

13. Kong LD, Meng LC, Wang LF, Shen Y, Wang P and Shang ZK: Evaluation of conservative treatment and timing of surgical intervention for mild forms of cervical spondylotic myelopathy. Exp Ther Med 6: 852-856, 2013.

14. Berg S and Tullberg T: Letter to the editor regarding Mannion, Brox, Fairbank. Comparison of spinal fusion and nonoperative treatment in patients with chronic low back pain: Long-term follow-up of three randomized controlled trials. Spine J 14: 1087, 2014.

15. Vieweg U and Sola S: Posterior lumbar interbody fusion with an interbody fusion spacer or cage. In: Manual of Spine Surgery. Vieweg U and Grochulla F (eds). Springer, Berlin, Heidelberg, pp377-384, 2012. https://doi.org/10.1007/978-3-642-22682-3_53.

16. Lee JC, Kim Y, Soh JW and Shin BJ: Risk factors of adjacent segment disease requiring surgery after lumbar spinal fusion: Comparison of posterior lumbar interbody fusion and posterolateral fusion. Spine 39: E339-E345, 2014.

17. Ong KL, Auerbach JD, Lau E, Schmier J and Ochoa JA: Perioperative outcomes, complications, and costs associated with lumbar spinal fusion in older patients with spinal stenosis and spondylolisthesis. Neurosurg Focus 36: E5, 2014.

18. Hu ZJ, Fang XQ, Zhou ZJ, Wang JY, Zhao FD and Fan SW: Effect and possible mechanism of muscle-splitting approach on multifidus muscle injury and atrophy after posterior lumbar spine surgery. J Bone Joint Surg Am 95: e192, 1-9, 2013.

19. Ma C, Wu JB, Zhao M, Dai WX, Wu DH, Wang ZH, Feng J, Liu C, Zhao QH and Tian JW: Posterior interbody fusion versus improved transforaminal lumbar interbody fusion in segmental spinal fixation for aged spondylolisthesis with lumbar spinal canal stenosis. Zhonghua Yi Xue Za Zhi 92: 620-623, 2012 (In Chinese).

This work is licensed under a Creative Commons Attribution-NonCommercial-NoDerivatives 4.0 International (CC BY-NC-ND 4.0) License. 